OPEN ACCESS

Edited by:

C. Cho,

Queen Elizabeth Hospital (QEH),

Hong Kong

Reviewed by:

Mohammadreza Hajjari,

Shahid Chamran University of Ahvaz,

The Hong Kong Polytechnic

University, Hong Kong

*Correspondence:

Keng Huang

Hkeng@126.com

Changmin Lin

cocolin@126.com

tThese authors have contributed equally to this work

Specialty section:

This article was submitted to

RNA,

a section of the journal

Frontiers in Genetics

Received: 07 February 2020

Accepted: 05 June 2020

Published: 04 August 2020

Citation:

Zhu N, Lin E, Zhang H, Liu Y, Cao G, Fu C, Chen L, Zeng Y, Cai B,

Yuan Y, Xia B, Huang K and Lin C (2020) LncRNA H19 Overexpression Activates Wnt Signaling to Maintain the Hair Follicle Regeneration

Potential of Dermal Papilla Cells.

Front. Genet. 11:694.

doi: 10.3389/fgene.2020.00694

\section{LncRNA H19 Overexpression Activates Wnt Signaling to Maintain the Hair Follicle Regeneration Potential of Dermal Papilla Cells}

\author{
Ningxia Zhu't, En Lin ${ }^{2,3+}$, Huan Zhang ${ }^{2+}$, Yang Liu' ${ }^{2}$, Guiyuan $\mathrm{CaO}^{1}$, Congcong Fu', \\ Le Chen ${ }^{2}$, Yang Zeng ${ }^{2}$, Bozhi Cai ${ }^{4}$, Yanping Yuan ${ }^{2}$, Bin Xia ${ }^{1}$, Keng Huang ${ }^{* \star}$ and \\ Changmin Lin ${ }^{2 * t}$
}

\begin{abstract}
'Department of Pathophysiology, Guilin Medical University, Guilin, China, ${ }^{2}$ Department of Histology and Embryology, Shantou University Medical College, Shantou, China, ${ }^{3}$ Department of Reproductive Center, First Affiliated Hospital, Shantou University Medical College, Shantou, China, ${ }^{4}$ Tissue Engineering Laboratory, First Affiliated Hospital, Shantou University Medical College, Shantou, China, ${ }^{5}$ Department of Emergency, Second Affiliated Hospital, Shantou University Medical College, Shantou, China
\end{abstract}

Androgenetic alopecia (AGA) is a common hair loss disorder resulting in seriously abnormal social interaction and psychological disorders. Transplantation with autologous dermal papilla cells represents a prospective therapy. However, the ability of dermal papilla cells to induce hair follicle development is lost upon cell culturing. Long non-coding RNAs (IncRNAs) are an important class of genes involved in various biological functions, are aberrantly expressed in disease and may play roles in the regulation of Wnt signaling, a critical pathway in maintaining the hair follicle-inducing capability of dermal papilla cells. Examination of dermal papilla cells by IncRNA microarray revealed that $\mathrm{H} 19$ was highly expressed in early passage dermal papilla cells compared with late-passage dermal papilla cells. In this study, we constructed H19-overexpressing dermal papilla cells to examine the role of $\mathrm{H} 19$ on hair follicle inductivity. Dermal papilla cells infected with lentivirus encoding H19 maintained their cell shape, and continued to display both multiple-layer aggregation and hair follicleinducing ability upon prolonged culture. $\mathrm{H} 19$ exerted these effects through inducing miR-29a to activate Wnt signaling by directly downregulating the expression of Wnt suppressors, including DKK1, Kremen2, and sFRP2, thereby forming a novel regulatory feedback loop between $\mathrm{H} 19$ and miR-29a to maintain hair follicle- inducing potential. These results suggest that IncRNA H19 maintains the hair follicle-inducing ability of dermal papilla cells through activation of the Wnt pathway and could be a target for treatment of androgenetic alopecia.

\footnotetext{
Keywords: dermal papilla cell, H19, Wnt, alopecia, hair follicle
}

Abbreviations: DP, dermal papilla; HF, hair follicle; IncRNA, long non-coding RNA; miRNA/miR, microRNA; WB, western blot; FISH, fluorescence in situ hybridization; LV, lentivirus; NC, negative control; DKK1, Dickkopf-1; Kremen2, Kringle containing transmembrane protein 2; sFRP2, secreted frizzled-related protein 2; SAHH, S-adenosylhomocysteine hydrolase; SEM, standard error of mean. 


\section{INTRODUCTION}

Androgenetic alopecia (AGA) is an extremely common type of hair loss affecting the appearance and mental state in both men and women (Wang et al., 2010; Vincenzi et al., 2019). However, current treatments, including topical or systemic drugs and surgical transplantation, have numerous limitations due to severe side effects or availability of donor follicles. Cellbased hair regeneration offers a possible alternative, but current techniques are not capable of providing sufficient numbers of cells for regeneration (Ohn et al., 2019). Mesenchyme-derived dermal papilla (DP) cells, are located at the base of the hair follicle and regulate both development and growth of hair follicles, making them a potential therapeutic candidate for use in treatment of AGA (Ohyama et al., 2010; Ohn et al., 2019). However, although early passage DP cells can induce hair follicle regeneration in vivo and vitro, they quickly lose the hair inductivity during passaging in vitro (Jahoda et al., 1984; Yang and Cotsarelis, 2010).

Recent research demonstrates the importance of long non-coding RNAs (lncRNAs) in the regulation of various biological processes, such as cell development, differentiation, disease, subcellular localization and cellular structural maintenance (Wang and Chang, 2011; Kornienko et al., 2013; Boon et al., 2016). Also, for the biology of hair follicle, specific lncRNAs, such as ANCR, TINCR, HOTAIR, SPRY4-IT1 have been identified to be involved in the regulation of the HF cycle (Wan and Wang, 2014). Bao et al. (2017) reported a total of $2143 \operatorname{lncRNAs}$ to be differentially expressed (fold change $>2.4$ ) between AGA and adjacent normal tissues in a Chinese male population. Our previous study analyzed the differential expression pattern in passage-4 vs. passage-10 DP cells in a lncRNA microarray. Interestingly, results showed five transcripts (ENST00000442037, uc001va.4, uc021qbz1, ENST00000439725, and ENST00000417089) from H19 gene were highly expressed in early passage DP4 cells with hair follicle-inducing ability (Lin et al., 2014).

It is known that $\mathrm{Wnt} / \beta$-catenin is a critical positive modulator in the maintenance of hair follicle regeneration by DP cells (Soma et al., 2012; Rishikaysh et al., 2014; Xiong et al., 2014) and H19 has been shown to play an important role in vascular smooth muscle cell proliferation and osteoblast differentiation by activating the Wnt/ $\beta$-catenin pathway (Liang et al., 2016; Zhang et al., 2018). In addition, lncRNA H19 expression promotes bladder cancer metastasis by associating with EZH2 to activate the Wnt/ $\beta$-catenin pathway (Luo et al., 2013). However, previous findings mainly focus on the mechanism of IncRNA in cancer and other diseases, or only on the expression patterns of IncRNAs in hair regeneration. Based on the high level expression of H19 in early passage cells and its close correlation with the Wnt signaling pathway, we used lentiviral transduction to overexpress H19 in DP cells and assessed viability and HF inducibility, as well as investigated the underlying regulatory mechanisms involving Wnt/ $\beta$-catenin, to determine the role of H19 in DP cell-induced HF induction in this study.

\section{MATERIALS AND METHODS}

\section{Ethical Issues}

The use of human scalp tissues was approved by the Ethics Committee of the First Affiliated Hospital, Shantou University Medical College. All participants provided written informed consent. Experiments with mice were performed with the permission of Shantou University Medical College.

\section{Isolation and Cultivation of DP Cells}

Human scalp tissues were obtained from individuals undergoing forehead rhytidectomy or debridement and suturing. Primary culture and subculture of DP cells were performed as previously described (Li et al., 2005). DP cells were cultured in Dulbecco's modified Eagle's medium (DMEM) containing 10\% fetal bovine serum (FBS, Invitrogen-Gibco) in a humidified atmosphere of $5 \% \mathrm{CO}_{2}$ at $37^{\circ} \mathrm{C}$, and were cultivated continuously. Cells used to confirm H19 expression and transfected with $\mathrm{H} 19$ overexpression plasmids were acquired from donors 8,20 , and 40 years of age, all of which were used at passage- 4 , passage- 8 , and passage- 10 . Cells for experiments applied to observe cell characteristics and infected with $\mathrm{H} 19$ overexpression lentivirus were obtained from donors $46,50,55$ years of age, and all were used at passage 36 and 10.

\section{Cell Transfection and Infection}

The full-length H19 sequence was inserted into the pcDNA3.1 vector (pcDNA3.1-H19) (GenePharma, Shanghai, China). A plasmid carrying a non-targeting sequence (pcDNA3.1) was used as a negative control. DP cells were transfected using Lipofectamine 3000 reagent (Invitrogen, CA, United States). The protocols of plasmid construction and transfection are following the manufacturer's instructions. Recombinant H19-expressing lentivirus encoding green fluorescent protein (GFP) (LV-H19) and the control lentiviral vector (GFP-lentivirus, LV-NC) were constructed by the GeneChem Company (Shanghai, China). To obtain stable cell lines, passage 3 DP cells were plated in $60 \mathrm{~mm}$ dishes and infected at a multiplicity of infection (MOI) of 20 when cell density reached $75 \%$ confluence. Medium was removed after $48 \mathrm{~h}$ and replaced with complete culture medium. Infection efficiency was confirmed by QPCR and fluorescence microscopic examination after infection. The primer sequences of pcDNA3.1-H19 and recombinant H19 lentiviral transfer vector were as follows: BamHI-F:CG CGGATCCAGTTAGAAAAAGCCCGGGCTAG; EcoRI-R:CC GGAATTCTTGCTGTAACAGTGTTTATTGATGATG. The detailed procedure of lentivirus construction is described in Supplementary File $\mathbf{S 1}$.

\section{Luciferase Reporter Assay}

To evaluate the influence of $\mathrm{H} 19$ on the Wnt/ $\beta$-catenin signaling pathway, a luciferase reporter plasmid pGL4.49[luc2P/TCF-LEF RE/Hygro] (Promega, United States) and pcDNA3.1/pcDNA3.1H19 as well as an internal control pGL4.74[hRluc/TK] vector (Promega, United States) were co-transfected into the passage 8 (DP8) cells at 70\% confluence. After $24 \mathrm{~h}$, luciferase reporter activity was measured 
with a Dual-Luciferase Assay System (Promega, Madison, WI, United States).

\section{RNA Extraction and Real-Time PCR}

Total RNA, including lncRNA/miRNA fractions, was isolated from DP cells or dorsal skins, with a miRNeasy Mini Kit (QIAGEN, Beijing, China) and the quality of the RNA was assessed with a NanoDrop 2000 spectrophotometer (Thermo Fisher Scientific, United States) at 260 and $280 \mathrm{~nm}$ (A260/280). GAPDH was used as an internal control to normalize lncRNA/mRNA levels and U6 for MiR-29a-3p. Primers used for H19 and other mRNAs were provided by Invitrogen and the sequences are presented in Supplementary Tables S1, S2. Forward primers for miR-29a-3p and U6 were provided by TIANGEN Biotech (Beijing) Co., Ltd. RNA from the samples was reverse transcribed using a PrimeScript ${ }^{\mathrm{TM}}$ RT reagent Kit with gDNA Eraser (Perfect Real Time) (TaKaRa, Dalian, China), or a miRcute miRNA First-Strand cDNA Synthesis kit (Tiangen, Beijing, China), according to the manufacturer's instructions. qRT-PCR was performed using a standard SYBR ${ }^{\circledR}$ Green PCR kit (RR820A, Toyobo Co. Ltd., Tokyo, Japan) or miRcute Plus miRNA qPCR Detection kit (Tiangen, Beijing, China) in a CFX96 ${ }^{\mathrm{TM}}$ Real-Time PCR Detection machine (BioRad, United States). Changes in expression were determined by the $2^{-\Delta \Delta}$ CT method.

\section{Animal Hair Follicle Induction}

NU/NU mice (6 weeks old) were obtained from Beijing Vital River Laboratory Animal Technology Co., Ltd., and were divided into three groups: a control group injected with normal DP cells (Con-DP4), a control group injected with DP cells transfected with control lentivirus (LV-NC-DP4), and an experimental group injected with DP cells infected with H19-overexpressing lentivirus (LV-H19-DP4). About 3-5 $\times 10^{4} \mathrm{DP}$ cells in $0.8 \mathrm{ml}$ DMEM containing $10 \%$ fetal bovine serum were injected subcutaneously into each mouse dorsum. Mice were euthanized by $\mathrm{CO}_{2}$ inhalation after 10 days and the implantation sites were biopsied for molecular and histological analyses.

\section{Fluorescence in situ Hybridization}

A Cy3-conjugated probe mix for lncRNA H19 was synthesized by GenePharma (Cy3-H19-Bio, Shanghai, China), and sequences were as follows $\left(5^{\prime}-3^{\prime}\right)$ : CTGTGCCTGCTACTAAATGA, ATGCTGTACTGTGCCAAG, ATGTCATGTCCTGTTGTCA, AAGCTAGAGGGTTTTGTGTC, CACACTCGTACTGAGAC TCA. Cells were fixed in $4 \%$ formaldehyde for $15 \mathrm{~min}$, treated using $0.1 \%$ TritonX-100 for $15 \mathrm{~min}$, and washed three times with PBS for $2 \mathrm{~min}$, then incubated with $1 \times$ saline sodium citrate. Next, the cells were dehydrated using a graded ethanol series and incubated with the Cy3-labeled $\mathrm{H} 19$ probe mix at $37^{\circ} \mathrm{C}$ overnight, and washed with $1 \times$ saline sodium citrate four times for 3 min each wash. Lastly, nuclei were stained with DAPI. Signals were observed under a fluorescence microscope (Nikon H600L, Japan).

\section{Western Blot}

For determining $\beta$-catenin levels in the nucleus and cytoplasm, nuclear, and cytoplasmic protein fractions of
DP cells were extracted using a NE-PER Nuclear and Cytoplasmic Extraction Kit (78835; Pierce Biotechnology, United States). Total protein from DP cells, following H19 transient transfection, and dorsal skin tissues from nude mice were also extracted. The BCA method was applied for quantifying protein concentration. RIPA buffer was used to lyse cells and tissues and SDS-PAGE was conducted to separate the cellular or tissue proteins. Antibodies and dilutions used were as follows: GAPDH (Abcam, ab9485, United States, 1:5000), TBP (CST 8515S, United States, 1:1000), $\beta$-catenin (Abcam, ab32572, United States, 1:1000), DKK1 (Abcam, ab109416, United States, 1:1000), Kremen2 (Abcam, ab156007, United States, 1:1000), sFRP2 (Abcam, ab86379, United States, 1:1000), Wnt3a (1:1000, 09-162, Millipore), and LRP6 (1:1000, orb373345, Biorbyt). Bands were visualized with SuperSignal ${ }^{\mathrm{TM}}$ West Femto Maximum Sensitivity Substrate (34095, Thermo Fisher Scientific) and a Universal Hood II gel imaging and image lab 3.0 analysis system (Bio-Rad, United States).

\section{Hematoxylin and Eosin (H\&E) Staining}

Dorsal skins from nude mice were harvested for histological analysis. Specimens were fixed with $4 \%$ paraformaldehyde, dehydrated through a graded series of ethanol, washed with xylene, and embedded in paraffin wax. Treated specimens were cut into $4 \mu \mathrm{m}$-thick sections and stained with hematoxylin and eosin for routine histology evaluation. Tissue was observed using bright field microscopy (Nikon H600L, Japan).

\section{Immunofluorescence Staining}

Skin tissue sections were incubated with blocking solution containing $10 \%$ donkey serum for $30 \mathrm{~min}$ at $37^{\circ} \mathrm{C}$ and then probed overnight at $4^{\circ} \mathrm{C}$ with a diluted primary antibody, followed by a secondary antibody for $1 \mathrm{~h}$. The primary antibodies used were: rabbit anti- $\beta$-catenin (1:200, ab32572, Abcam, Cambridge, United Kingdom), rabbit anti-Wnt3a (1:200, 09-162, Millipore), and rabbit anti-LRP6 (1:100, orb373345, Biorbyt). The secondary antibody used was Alexa Fluor 488-conjugated antibody (1:150, Jackson). DNA was stained with 4', 6-diamidino-2-phenylindole (DAPI) $(1 \mu \mathrm{g} / \mathrm{ml}, \mathrm{C} 1005$, Beyotime, Jiangsu, China) for $10 \mathrm{~min}$ at room temperature. All images were collected using a fluorescence microscope (Nikon H600L, Japan).

\section{Biotin-Labeled RNA Pull-Down and Mass Spectrometry Analysis}

RNA pull-down assay was performed as previously described (Bierhoff, 2018; Torres et al., 2018). Briefly, different segments of H19 were constructed with pcDNA3.1 plasmid, which also contains the T7 promoter. The plasmids were linearized using EcoRI. The anti-sense sequences are as follows: F:taatac gactcactatagggTTGCTGTAACAGTGTTTATTG; R:AGTTAG AAAAAGCCCGGGCTAG. RNA was precipitated and incubated with cell lysis buffer and biotin-labeled oligonucleotide for $2 \mathrm{~h}$ at RT. The RNA-protein complex was washed and eluted. The samples were separated using electrophoresis and identified 
by mass spectrometry, then sequences were retrieved in the Universal Protein Resource (UniProt) for human databases and the National Center for Biotechnology Information (NCBI) databases. To reduce the probability of false peptide identification, only peptides at a 95\%, confidence interval $(P<$ 0.05 ) with a false discovery rate (FDR) estimation $1.04 \%$ were counted as being successfully identified.

\section{Statistical Analysis}

Data are expressed as mean \pm SEM and analyzed by the two-tailed Student's $t$-test or one-way analysis of variance (ANOVA). A $P<0.05$ was considered statistically significant. All experiments were repeated at least three times, and for each experiment, samples were analyzed in triplicate.

\section{RESULTS}

\section{LncRNAH19 Differs Between Early and Late Passage DP Cells}

In our previous lncRNA by microarray profiling (Lin et al., 2014) we reported that five transcripts from the H19 gene were up-regulated in early passage DP cells (DP4), which were HF-inducible. Here, we examined the lncRNA expression between early and late passage DP cells (DP4 and DP10) via QPCR and FISH. As shown in Figure 1, lncRNAH19 was increased in DP4 cells compared with that in DP10 cells (Figure 1A). Furthermore, high levels of lncRNAH19 were located in the nucleus of DP4 cells (Figure 1B). The above results
A

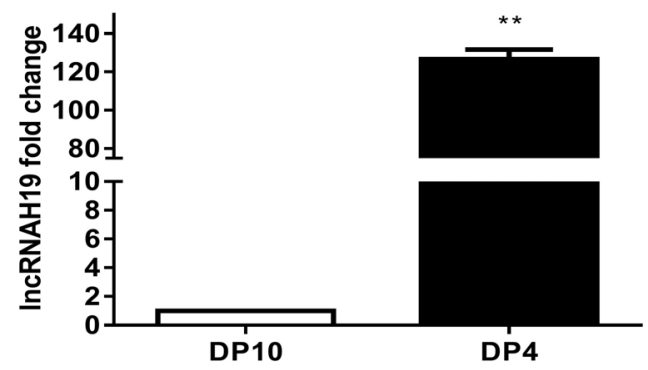

B InCRNAH19

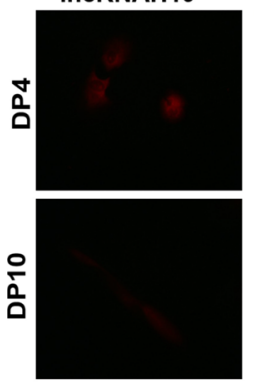

DAPI
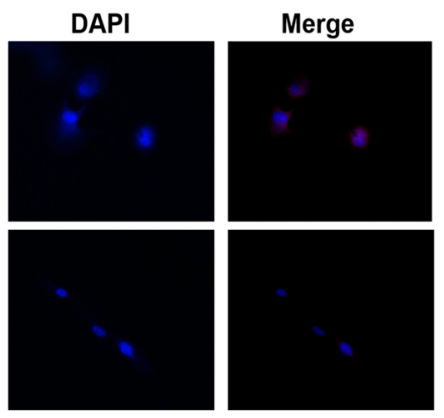

C

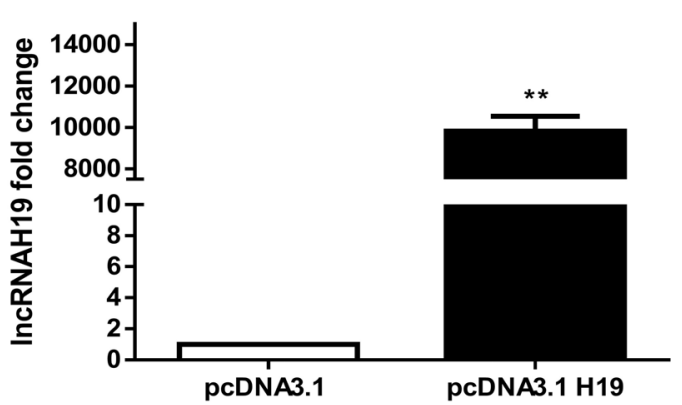

D

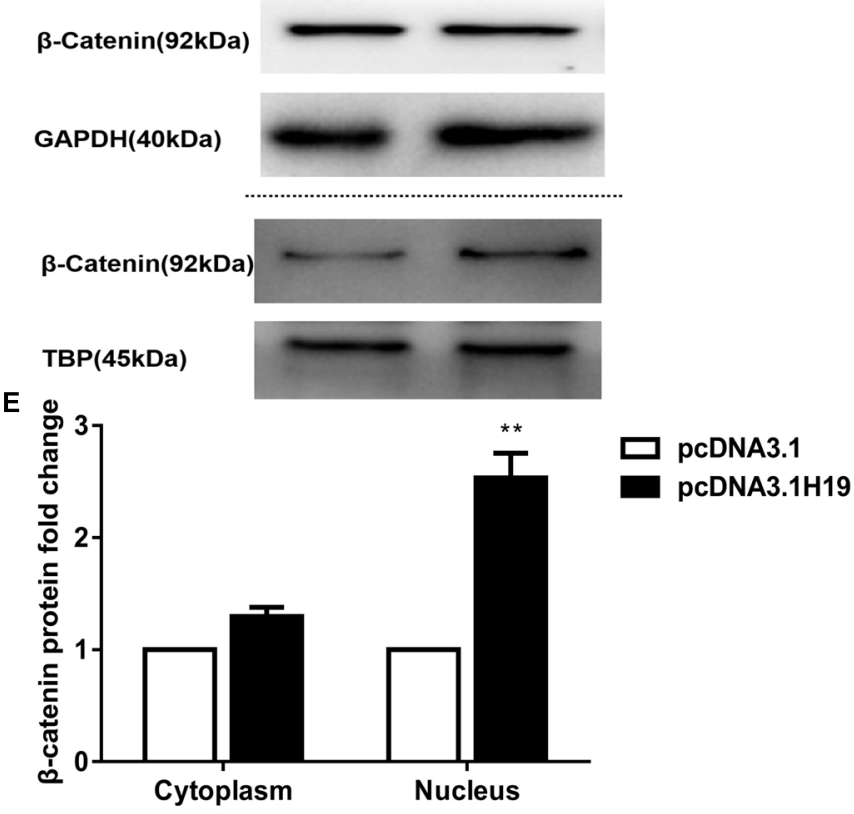

$\mathbf{F}$

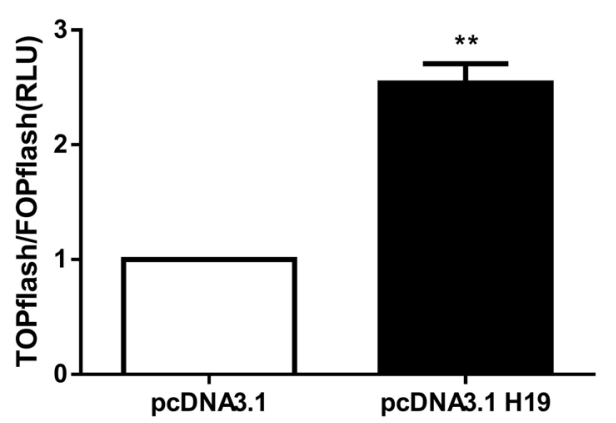

FIGURE 1 | Differential expression of IncRNA H19 between early and late passage DP cells and effect of IncRNAH19 overexpression on the Wnt/ $\beta$-catenin signaling pathway in DP cells. (A) QPCR verification the increased expression of IncRNAH19 in early passage DP cells (DP4) that show HF-inductivity ability. (B) FISH showing increased expression of IncRNAH19, in early passage DP cells (DP4), is mainly located in the nucleus ( $\times 40)$. (C) QPCR confirming that $\mathrm{H} 19$ was highly expressed in DP4 cells after being transfected with pcDNA3.1H19. (D,E) Compared with the pcDNA3.1 group, $\beta$-catenin expression in the nucleus was upregulated significantly after H19 overexpression (B, upper), whereas no obvious changes could be found in the expression of $\beta$-catenin in the cytoplasm (B, lower). (F) Luciferase reporter assay showed Wnt/ $\beta$-catenin signaling-dependent reporter gene transcription was dramatically increased after H19 overexpression in DP8 cells. Data shown represent the mean \pm SEM of three independent experiments. ${ }^{\star \star} P<0.01$, pcDNA3.1, mock-vehicle control group, pcDNA3.1H19 overexpression group. 
suggested an involvement of $\mathrm{H} 19$ in regulating DP cell HF inducibility.

\section{Overexpression of LncRNAH19 Activates the Wnt/ $\beta$-Catenin Signaling Pathway}

The Wnt signaling pathway has been shown to be crucial for HF inducibility of DP cells and it is closely correlated with H19 (Soma et al., 2012; Lin et al., 2014; Rishikaysh et al., 2014; Xiong et al., 2014). Thus, we investigated the effect of $\mathrm{H} 19$ on the Wnt signaling pathway. Considering the slow proliferation rate and vulnerability of DP10 cells, we constructed an H19 expression plasmid (pcDNA3.1-H19), then transfected it or pcDNA3.1 empty vector into DP4 cells, then examined the expression and nuclear translocation of $\beta$-catenin and performed a Wnt reporter assay on DP8 cells. After $24 \mathrm{~h}$, Results showed a significantly higher level of $\mathrm{H} 19$ gene expression in pcDNA3.1H19-transfected DP4 cells (Figure 1C). Furthermore, overexpression of $\mathrm{H} 19$ in DP4 cells upregulated $\beta$-catenin expression in the nucleus (Figures 1D,E). Additionally, TCF/LEF transcriptional activity of the luciferase reporter assay was increased by overexpressing H19 (Figure 1F). These results suggest lncRNA H19 activates the $\mathrm{Wnt} / \beta$-catenin pathway to positively impact the DP cell HF inducibility.

\section{H19 Overexpression Activates Wnt Signaling by Upregulating MiR-29a-3p in DP Cells}

MiR-141, miR-22, and miR-29a were all reported to be target genes of H19 and are closely correlated to Wnt signaling (Jia et al., 2016; Gong et al., 2018; Wang et al., 2018). Our previous work showed miRNA-195-5p suppressed the Wnt/ $\beta$-catenin pathway, possibly being responsible for the loss of HF-inducing ability of DP cells in culture (Zhu et al., 2018). We compared the expression of miR-141, miR-22, miRNA-195-5p, and miR29a following transfection of the H19 plasmid into DP4 cells. Interestingly, miR-29a-3p expression was significantly elevated in H19-overexpressing DP cells $(P<0.01)$ (Figure 2A), while the others showed no change (data not shown). MiR-29a$3 p$ target genes, such as Dikkopf-1 (DKK1), Kremen2, and secreted frizzled related protein 2 (sFRP2), are key factors contributing to inactivation of Wnt signaling (Kapinas et al., 2010; Nagano et al., 2013). We observed that mRNA levels of DKK1 and sFRP2 were significantly decreased, and Kremen2 was

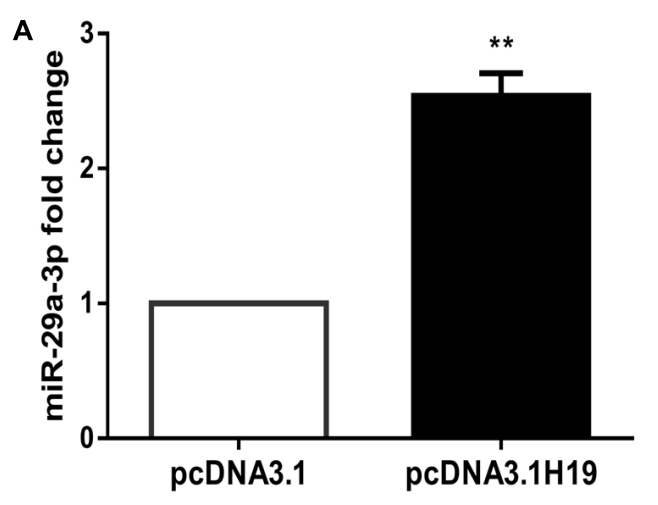

C

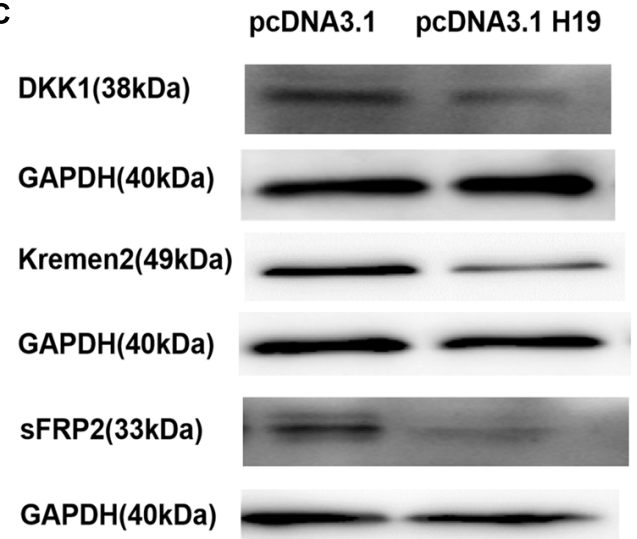

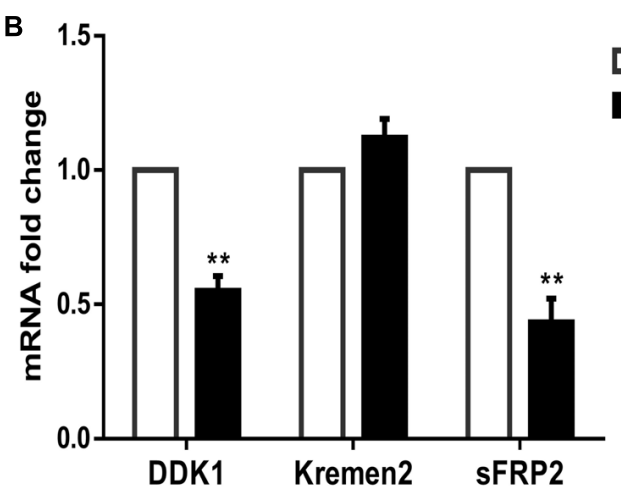

pcDNA3.1

pcDNA3.1H19

。

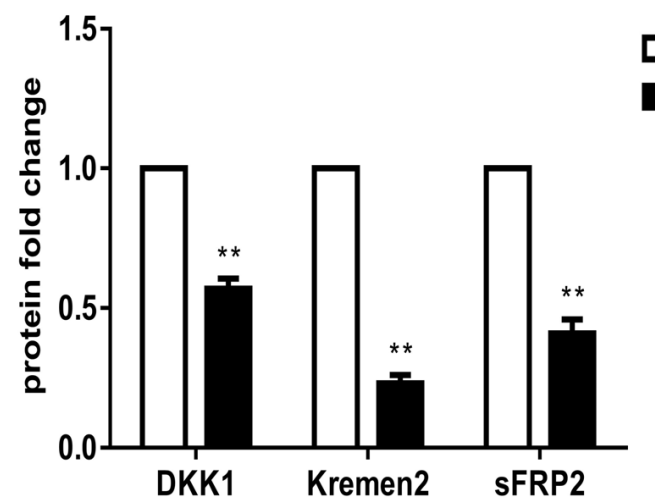

FIGURE 2 | LncRNAH19 overexpression activates Wnt signaling by upregulating miR-29a-3p in DP4 cells in vitro. (A) LncRNAH19 overexpression upregulated the level of miR-29a-3p. (B) QPCR showed that DKK1 and sFRP2 were down-regulated, but Kremen2 mRNA expression was slightly increased when H19 was overexpressed in DP cells. (C) LncRNAH19 overexpression decreased Dkk1, Kremen2, and sFRP2 protein levels compared with the mock-vehicle group. (D) Quantification of Dkk1, Kremen2, and sFRP2 protein expression levels. Data shown represent the mean \pm SEM of three independent experiments. ${ }^{\star \star} P<0.01$. 
slightly increased in H19-overexpressing DP4 cells (Figure 2B). In addition, western blot analysis of Dkk1, Kremen2, and sFRP2 showed robust reductions in protein level compared with the mock-vehicle group $(P<0.01)$ (Figures 2C,D). The above results show that miR-29a-3p may be the H19 target through which H19 regulates Wnt signaling in DP cells.

\section{Overexpression of H19 Maintains DP Cell Viability in vitro and HF-Inducing Ability Upon Passaging}

To address the critical role of H19 in the HF-inducing ability of DP cells, we transduced DP cells, isolated from elderly patients, with H19 overexpression recombinant lentiviruses, then cultivated the cells continuously. Compared with DP cells used in above experiments, results showed that DP4 cells lost the aggregative behavior and HF-inducing ability when subcutaneously injected into the backs of mice, possibly due to the ages of the DP sources (data not shown). After infecting early passage DP cells (DP3) with recombinant lentiviruses, QPCR showed a significantly upregulated level of H19, and GFP fluorescence, indicating high infection efficiency (Figures 3A,B). Interestingly, the DP3 cells transduced with H19-expressing lentivirus still maintained a long fusiform, fibroblast-like shape at passage-6, which is crucial for their HF-inducing ability, whereas the control DP cells did not (Figures 3C-E).

Next, we tested for HF-inducing ability of DP4 cells infected with $\mathrm{H} 19$ lentiviruses at DP3. Mice were divided into three groups: a normal DP4 cell group (Control-DP4), a control virusinfected DP4 cell injection group (LV-NC-DP4), and an H19 lentivirus-infected DP4 cell injection group (LV-H19-DP4). After 10 days of treatment, a white hair coat with a hair length of

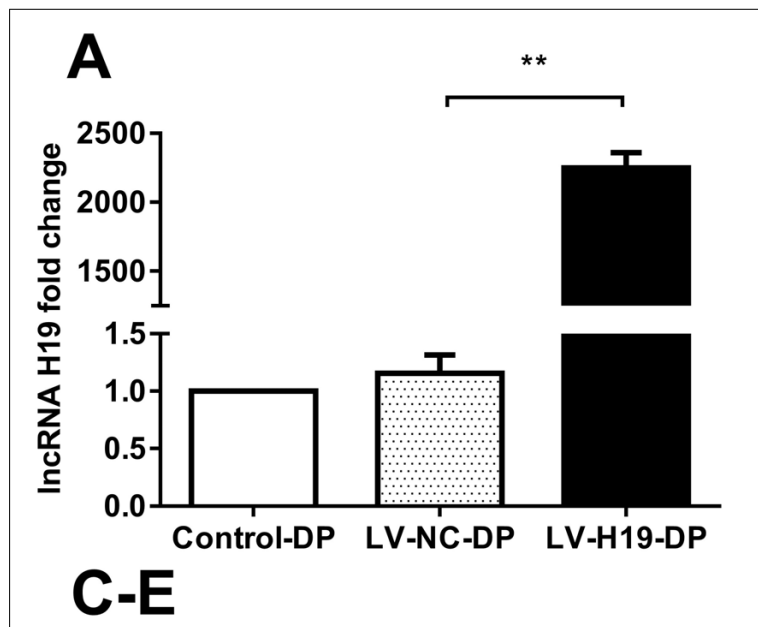

B
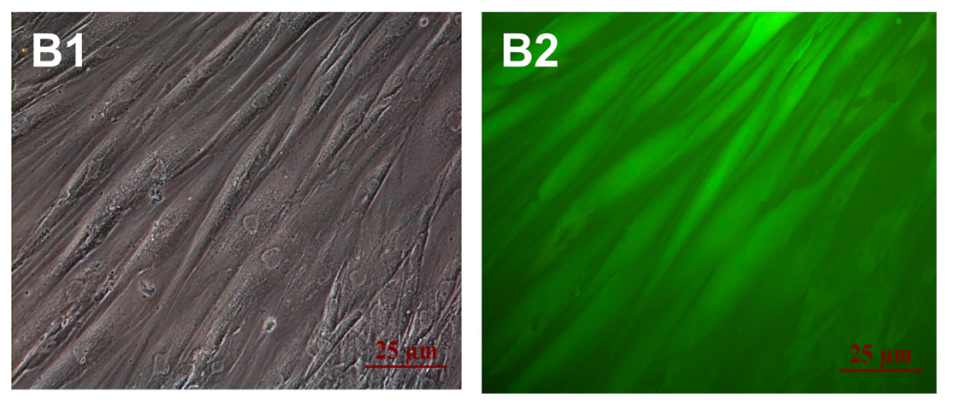

F-H
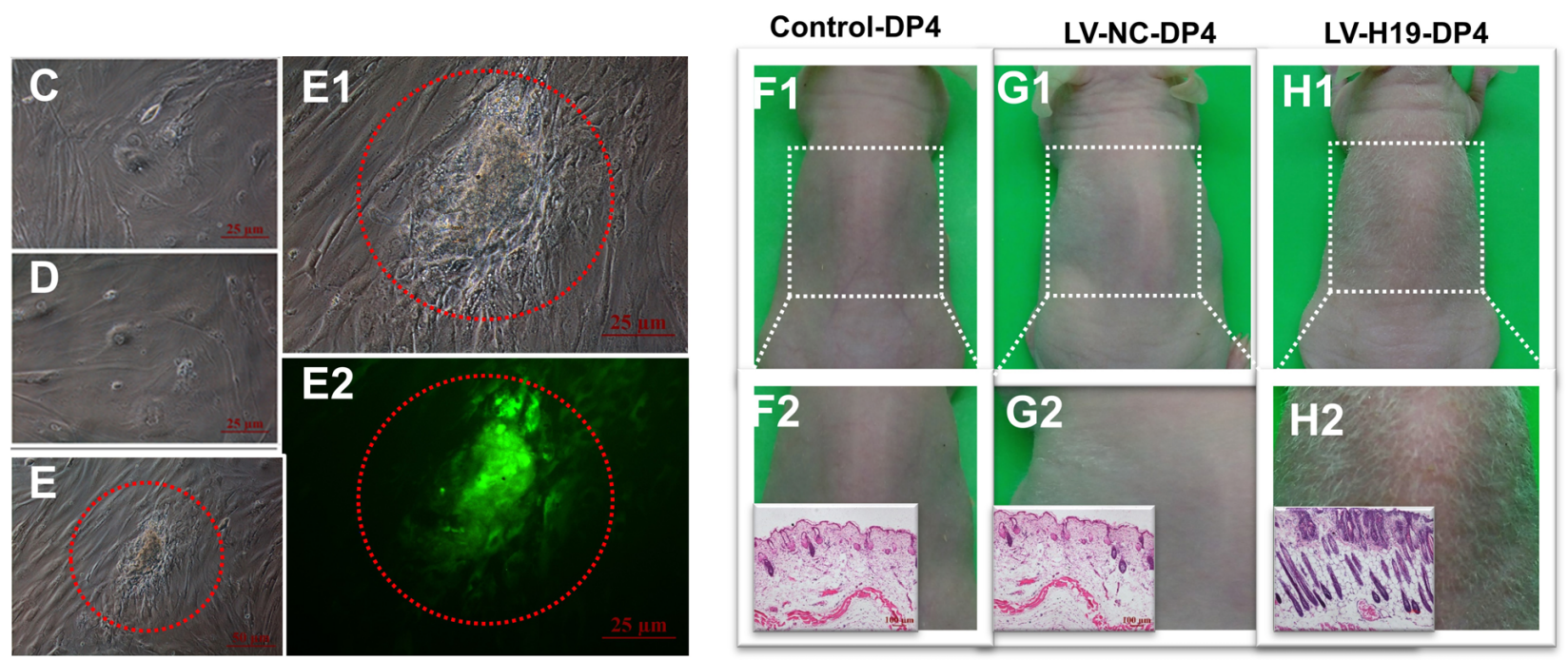

FIGURE 3 | Effects of IncRNAH19 overexpression on maintenance of DP cell viability in vitro and HF-inducing ability in vivo. (A) H19 lentivirus upregulated the level of H19. (B) GFP fluorescent signal showed high infection efficiency (left: bright field; right: fluorescence, scale bar, $25 \mu \mathrm{m})$. (C-E) After infection of DP3 cells with LV-H19 and continuous culture, LV-H19-DP6 cells maintained aggravative behavior (e, red circle), but Control-DP6 or LV-NC-DP6 cells did not (C,D). (F-H) LV-H19-DP4 cells induced hair generation on NU/NU mice backs after 10 days, with histological examination revealing HF structures, while the other two groups showed no hair growth. Data shown represent the mean \pm SEM of three independent experiments. $n=8$ mice per group. ${ }^{\star \star} P<0.01$. Control-DP4, normal DP4 cell-injected group, LV-NC-DP4, control virus-infected DP4 cell-injected group, LV-H19-DP4, the H19 overexpression lentivirus-infected DP4 cell-injected group. 
0.5-0.6 cm was observed in LV-H19-DP4-injected nude mice. Histology revealed large abnormal HF structures in the implanted sites, while control groups did not show any observable change (Figures 3F-H). Consequently, H19 expression inhibits the reductions in in vitro DP cell viability and in vivo HF-inducing ability that normally occur upon passage.

\section{LncRNA H19/MiR-29a Sustains HF-Inducing Effects of DP Cells in vivo by Regulating the Wnt Signaling Pathway}

To clarify whether miR-29a was involved in maintenance of HF inducibility in vivo, QPCR and western blot analysis were used to detect the RNA and protein expression patterns of miR-29a and its target genes after H19 overexpression by lentivirus transduction. Compared with control groups, miR29a-3p expression was dramatically elevated (Figure 4A), and its target genes Dkk1 and Kremen2 were decreased at both the mRNA and protein levels in the LV-H19-DP4 group. Additionally, sFRP2 protein level was significantly reduced (Figures 4B-D). We also observed the expression pattern of $\beta$-catenin, Wnt3a and LRP6, key factors of $\mathrm{Wnt} / \beta$-catenin signaling, in H19-expressing lentivirus-injected mouse dorsal skin. Results showed that $\beta$-catenin, Wnt3a and LRP6 mRNA and protein levels were significantly upregulated in the LV-H19DP4 group (Figures $\mathbf{5 A}-\mathbf{C}$ ), whereas the location of $\beta$-catenin, Wnt3a, and LRP6 were mainly in the ORS, IRS and DP matrix, other than the epidermis, indicating an active anagen phase of the hair follicle cycle (Figure 5D). These results suggest an important role for $\mathrm{H} 19 / \mathrm{miR}-29 \mathrm{a} / \mathrm{Wnt}$ signaling in regulating DP cell-mediated HF induction.

\section{LncRNA H19 Combines With SAHH Protein in DP Cells}

Research has shown $\mathrm{H} 19$ to bind and inhibit S-adenosylhomocysteine hydrolase (SAHH) to influence the methylation of targeted genes by DNMT, and thus may be a potential mechanism of regulating miR-29a (Zhou et al., 2015). To testify this, biotin-labeled RNA pull-down and mass spectrometry analysis were applied. First, electrophoresis confirmed the size of H19 pcDNA3.1 plasmid and H19 antisense chain PCR product, which were about 5428 and 2362 bp in length (Figures 6A,B). Secondly, Coomassie brilliant blue staining showed the differential protein bands between sense group and antisense group to be mainly located near $48 \mathrm{kDa}$ (Figure 6C). To exclude non-specific binding, the results of mass spectrometry were searched in the database and compared with the results of the antisense chain. This resulted in 97 proteins
A

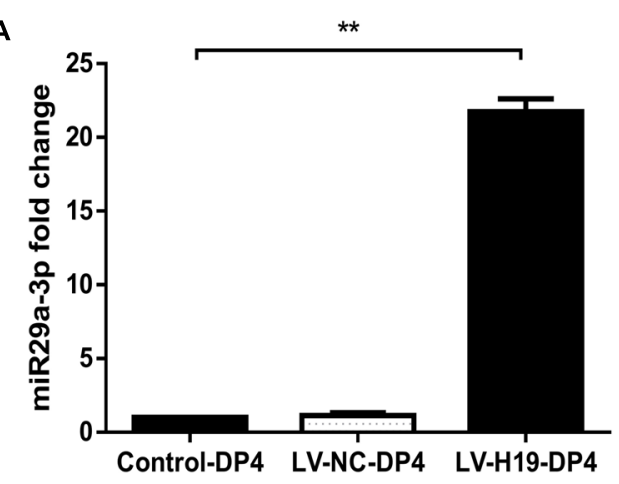

C

DKK1(38kDa)

GAPDH(40kDa)

Kremen2(49kDa)

GAPDH(40kDa)

SFRP2(33kDa)

GAPDH(40kDa)
Control-DP4 LV-NC-DP4 LV-H19-DP4
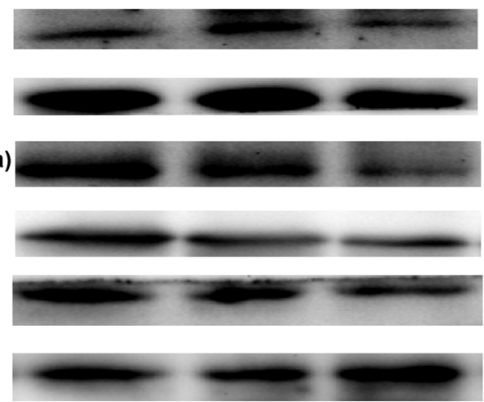

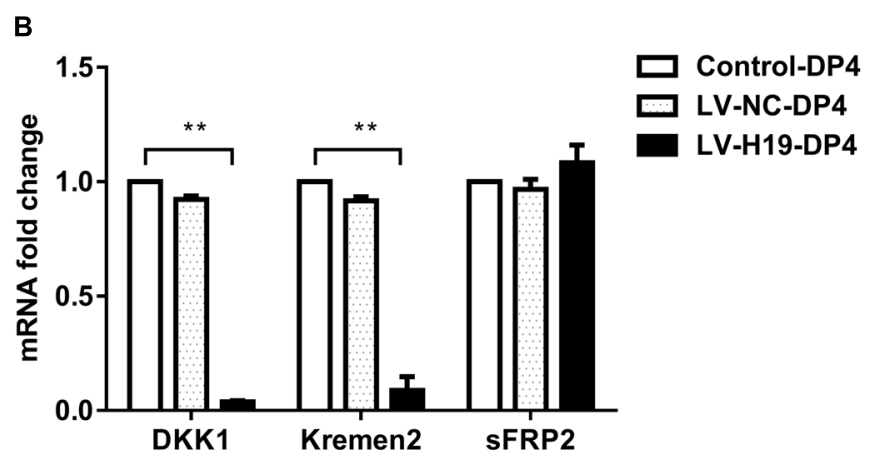

D

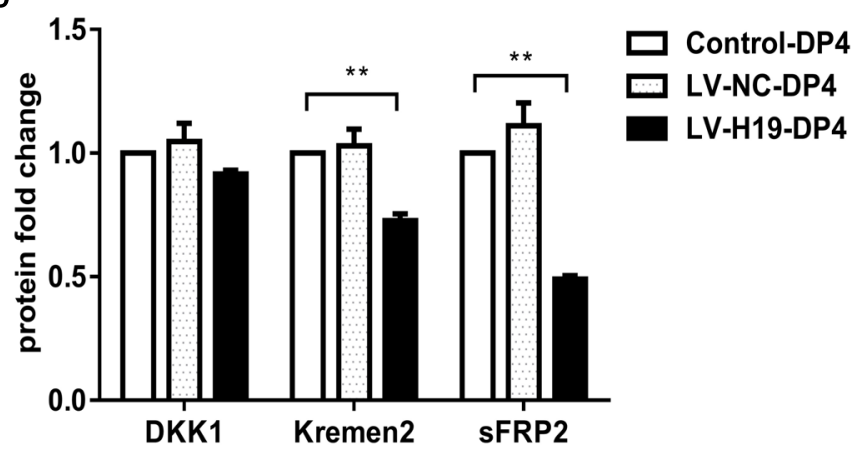

FIGURE 4 | Overexpression of H19 upregulates miR-29a and reduces the expression of its target gene involvement in Wnt signaling in skin of NU/NU mice. (A) Injection of DP4 cells transfected with LV-H19 uprelated the level of miR-29a-3 in the skin. (B) QPCR showed that DKK1 and Kremen2 were down-regulated, but SFRP2 mRNA expression slightly increased following transduction of DP4 cells with LV-H19. (C) LncRNAH19 overexpression significantly decreased Kremen2, and sFRP2 protein levels, while the level of DKK1 was reduced slightly in the skin. (D) Dkk1, Kremen2, and sFRP2 protein expression levels were quantified. Data shown represent the mean $\pm \mathrm{SEM}$ of three independent experiments. ${ }^{* \star} P<0.01$. 


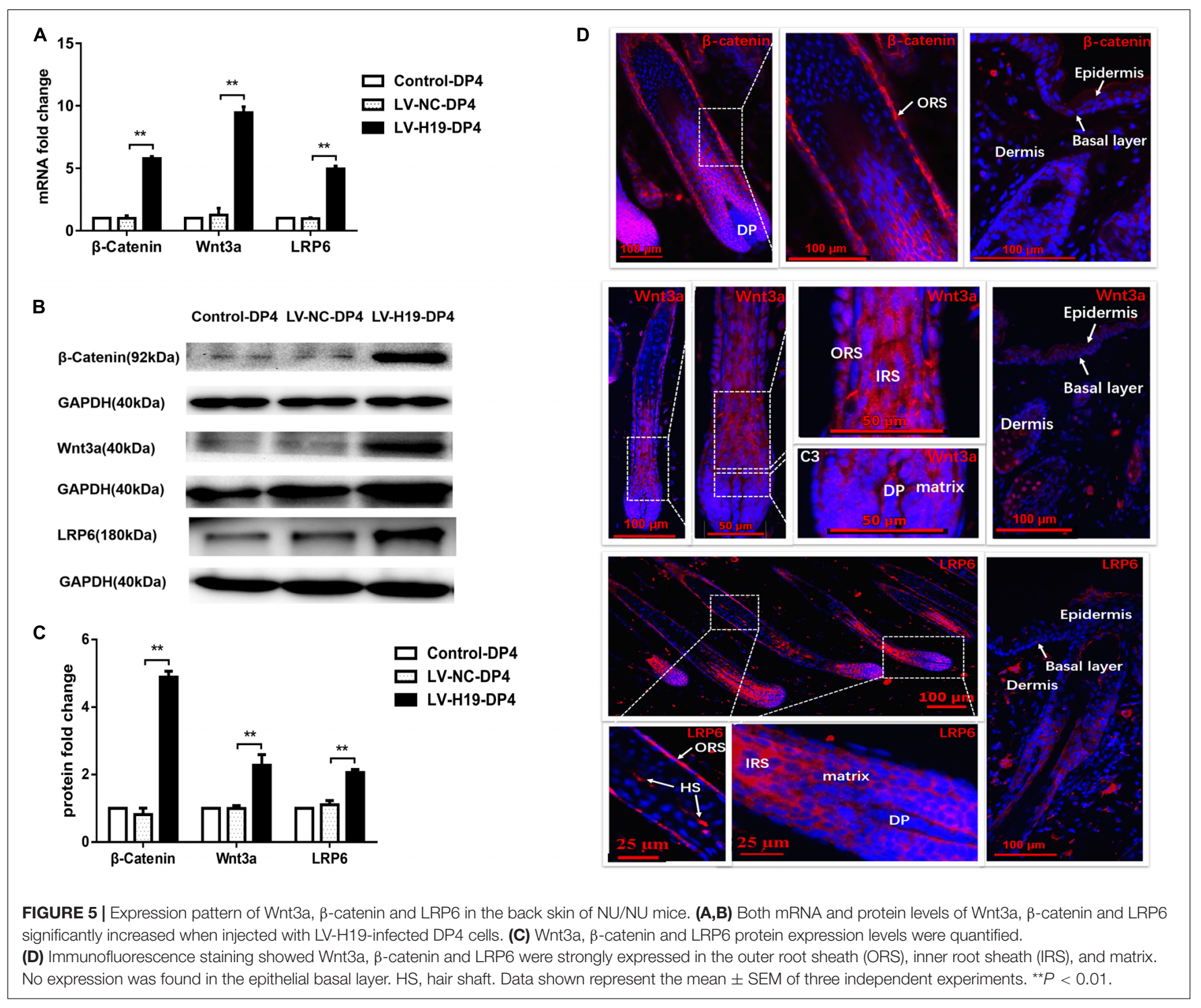

showing specific binding with $\mathrm{H} 19$, including $\mathrm{SAHH}$ protein in human DP cells (Figure 6D and Supplementary Table S3).

\section{DISCUSSION}

Recently, DP cells have become an attractive means of treating of AGA in adult human HF regeneration, partly due to their easy expansion to meet urgent clinical requirements. Here, we show that lncRNA H19 maintains the competence of DP cells to induce HF growth by activating Wnt signaling, indicating $\mathrm{H} 19$ is a probable marker for hair loss in the early stages and could have potential for hair loss treatment. Jahoda et al. (1984) demonstrated that low-passage rodent DP cells exhibit HF-inducing capability, but gradually lose the ability during passaging. Also, they found intact human DP cells could induce HF regeneration, and Krugluger et al., 2005. proposed human DP cells at low passage could induce HF-like structure formation in human skin when co-cultured with outer sheath keratinocytes (Jahoda et al., 2001; Krugluger et al., 2005). Interestingly, histopathologic examination has found nude mice injected with adult human DP cells show evidence of hair growth, but fail to show hair emerging from the injected site (Nilforoushzadeh et al., 2017). Our study demonstrates early passage human DP cells (DP14) show HF-inducing capability 10 days after injection into the back of NU/NU mice (Lin et al., 2014). The probable explanations for the observed differences between the reported results are the donor's age and species used. Also, in this study, H19-overexpressiong DP4 cells from elderly donors, showed no HF inductive ability, whereas in our study and H19 overexpression experiments, the DP4 cells were HFinducing. Differences could possibly involve the mechanism of senescence. It has been reported that DP cells from balding scalps undergo pre-senescence, and show higher senescence-associated $\beta$-Gal activity (Upton et al., 2015) whereas inhibiting p21 


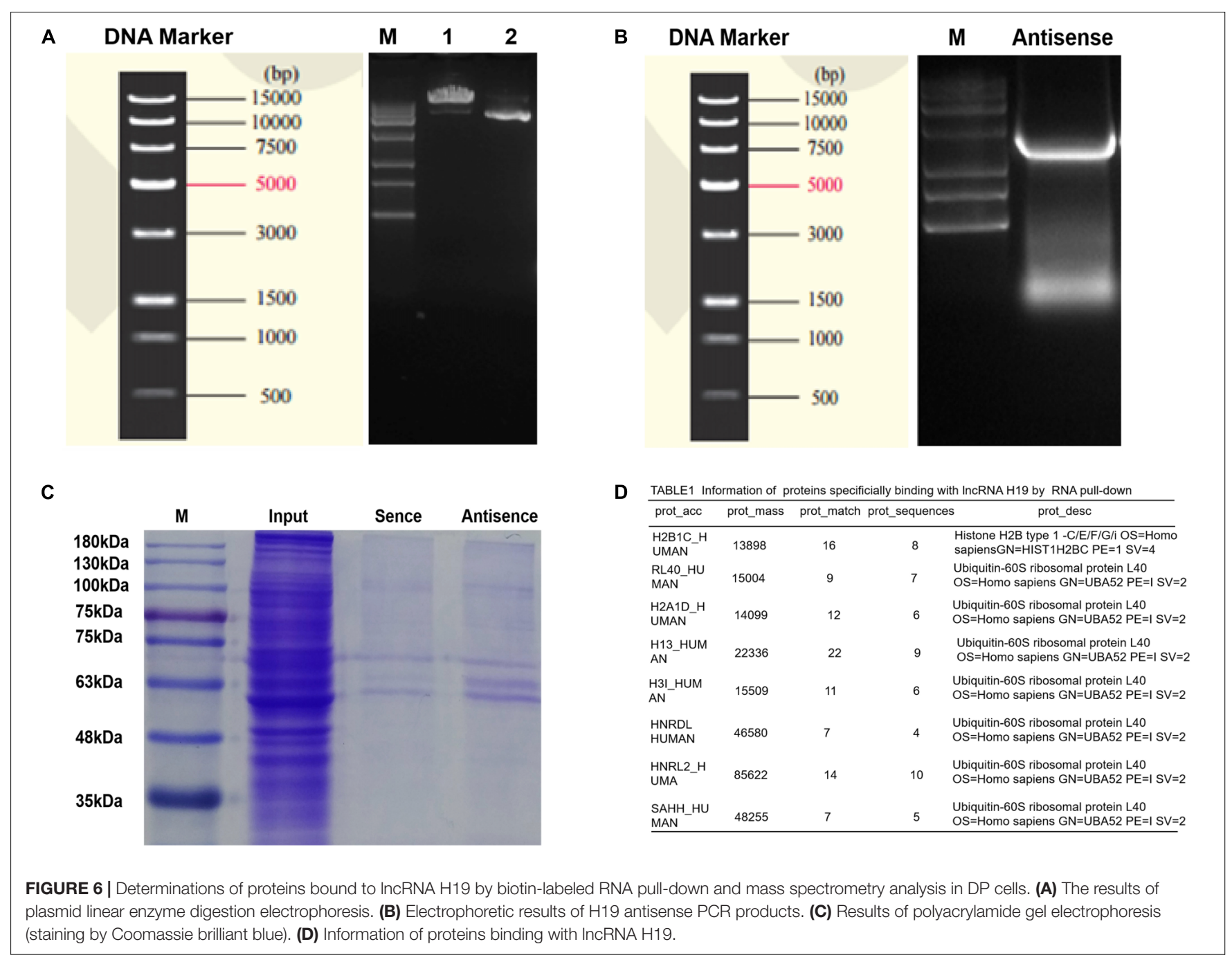

activated kinase 1 (PAK1) indicated growth-promoting activity (Nozomi et al., 2017).

In a previous study, we determined a high expression level of lncRNA H19 together with HOTAIR by microarray analysis in DP cells (Lin et al., 2014) and the present study confirms their expression pattern by QPCR. We found that H19 is significantly up-regulated in early passage DP cells, which is consistent with the microarray results, but HOTAIR is unchanged (data not shown). Moreover, FISH showed increased levels of lncRNAH19, identical to the microarray results, which is mainly located in the nucleus in DP4 cells. Furthermore, we investigated the effect of H19 expression on DP cell viability in vitro and HF-inducing ability concomitant with cell passage in vivo. In the experimental group, after H19 was overexpressed from 3rd passage DP cells onward, the cell shape, proliferation and multi-layer aggregation were maintained until passage-6. Notably, the ability of DP cells to induce HF formation is dependent on their aggregative growth (Cheng et al., 2017). Moreover, HF-inducing ability is observed with 4th passage DP cells, overexpressing H19, but not with control DP cells in passage 4, following injection into NU/NU mice. Using high-yield extracellular vesicle-mimetic nano-vesicles (EMNVs) as an effective nano-drug delivery system for lncRNA, EMNVs with a high content of lncRNA-H19 (H19EMNVs) induced structures resembling HFs (Tao et al., 2018). LncRNA-H19 transcript expression is dramatically higher at the anagen phase than that at both telogen and catagen phase in goats (Zhu et al., 2017). However, knockdown of H19 with siRNA was difficult to observe reduced expression pattern, possibly due to siRNA knockdown of lncRNAs can be difficult according to location or secondary structure in specific DP cells (data not shown). Nevertheless, our results indicate the potential of H19 in maintaining the HF-inducing competence of DP cells.

The Wnt/ $\beta$-catenin signaling pathway plays an important role in promoting HF regeneration in DP cells (Soma et al., 2012; Rishikaysh et al., 2014; Xiong et al., 2014). Emerging evidence suggests a close correlation between $\mathrm{H} 19$ and the Wnt/ $\beta$-catenin pathway (Liang et al., 2016; Li et al., 2017; Zhang et al., 2017, 2018). Our results suggest $\beta$-catenin is increased in the nucleus and TCF/LEF transcriptional activity is significantly elevated, indicative of an activated Wnt signaling pathway in H19overexpressing DP cells (Komiya and Habas, 2008). Additionally, $\beta$-catenin, Wnt3a and LRP6 levels are upregulated in HFs formed 
from LV-H19-DP4 cells, and the locations are mainly in the ORS, IRS and DP matrix, other than the epidermis, indicating activation of anagen phase of the hair follicle by H19 (Lin et al., 2015; Rognoni et al., 2016).

The mechanisms mediated by lncRNAs include chromatin modification, genomic imprinting, and functioning as sponge regulators of miRNA to target genes (Akhade et al., 2017). Here, we found the level of miR-29a is increased after H19 overexpression in DP cells. In addition, high levels of miR-29a directly suppress the expression of Dkk1, Kremen2, and sFRP2, which are suppressors of the Wnt pathway, thus activating the Wnt signaling pathway, in accordance with previous studies (Kapinas et al., 2010; Nagano et al., 2013). Still, miR-29a has been reported to inhibit hair follicle stem cell lineage progression by spatiotemporally suppressing Wnt and BMP Signaling (Ge et al., 2019). The discrepancy is probably due to the different cells, different animal models, or intervention strategy used in the research. Also, there maybe exist other regulatory mechanisms between $\mathrm{H} 19$ and miR-29a. Compared with the inhibiting effect of lncRNAH19 on miRNAs (Jia et al., 2016; Lu et al., 2016; He et al., 2017). H19 associates with the hnRNP U/PCAF/RNA Pol II protein complex to positively regulate the miR-200 family by increasing histone acetylation (Zhang et al., 2013). SAHH is shown to be the only enzyme to hydrolyze S-adenosylhomocysteine (SAH) in mammals, which acts as an inhibitor of methyl reaction (Zhou et al., 2015).
Interestingly, $\mathrm{H} 19$ has been indicated to bind and inhibit $\mathrm{SAHH}$, and H19 knockdown activates SAHH, leading to increased DNMT-mediated methylation of a targeted gene. Genome-wide methylation profiling has revealed that methylation changes at numerous gene loci, consistent with SAHH modulation by $\mathrm{H} 19$ (Zhou et al., 2015). DNA methylation is generally associated with chromatin condensation, which plays an important role in silencing genes (Ikegami et al., 2009). Also, epigenetic gene inactivation associated with methylation of promoter CpGislands is common to miRNA genes (Loginov et al., 2015). Studies show expression of miRNA genes is also regulated via epigenetic mechanisms, including CpG-island methylation (Kozaki et al., 2008; Ando et al., 2009). According to a number of publications, methylation is involved in regulating more than $11 \%$ of miRNA genes (Kunej et al., 2011; Loginov et al., 2015). Of relevance, the miR-29 family has been found to regulate DNA methylation pathways (Fabbri et al., 2007; Garzon et al., 2009; Robaina et al., 2015). In our study, RNA pull-down results showed that there is specific binding between $\mathrm{H} 19$ and SAHH in DP cells, which is identical to a previous study (Zhou et al., 2015). Taken together, we hypothesize that when $\mathrm{H} 19$ is overexpressed, SAHH activity is attenuated, which leads to accumulation of SAH and preventing DNMT from methylating the CpG island within the miR-29a gene promoter (Jiang et al., 2014). The miR-29a gene, being methylated in non-HF-inducing DP cells, becomes demethylated

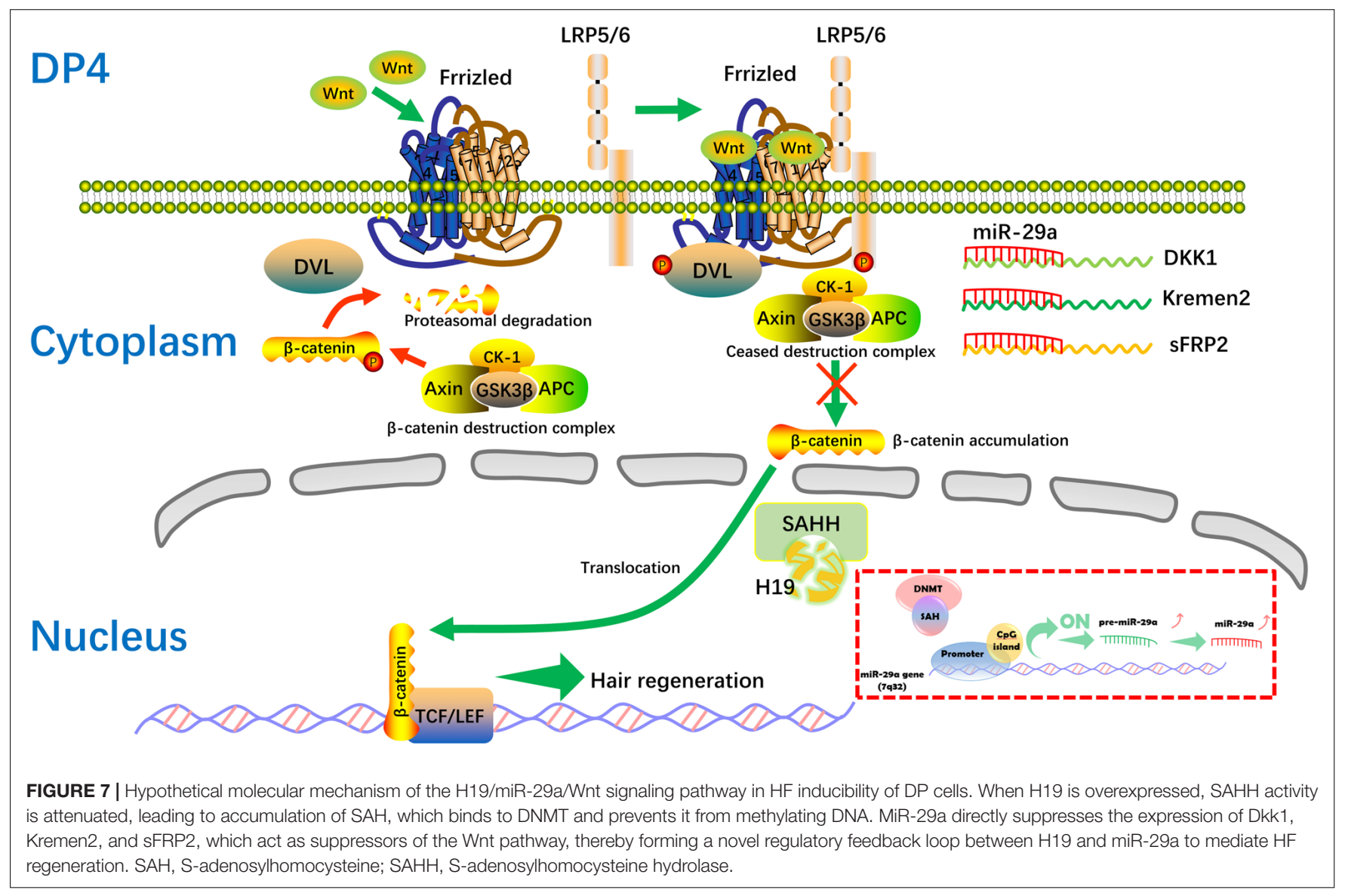


and is actively expressed. Restored expression of miR-29a in non-HF-inducing DP cells would result in enhanced potential to maintain hair follicle regeneration, particularly through reducing expression of the DKK1, sFRP2, and KREMEN2, which are inhibitors of the $\mathrm{Wnt} / \mathrm{\beta}$-catenin signaling pathway. Further studies will be engaged to describe the mechanism of regulation between H19 and miR-29a in DP cells (Figure 7).

\section{CONCLUSION}

In conclusion, this study explores the crucial role of H19 and miR-29a in the Wnt signaling pathway pertaining to $\mathrm{HF}$ regeneration in vitro and vivo, suggesting a possible strategy for improving the therapy of AGA patients. Thus, more comprehensive functional and mechanistic studies will be necessary and worthwhile.

\section{DATA AVAILABILITY STATEMENT}

All datasets generated for this study are included in the article/Supplementary Material.

\section{ETHICS STATEMENT}

The studies involving human participants were reviewed and approved by the Ethics Committee of the First Affiliated Hospital. Written informed consent to participate in this study was provided by the participants' legal guardian/next of kin. The animal study was reviewed and approved by Ethics Committee of the Shantou University Medical College.

\section{AUTHOR CONTRIBUTIONS}

NZ, EL, and HZ performed the experiments. YL, GC, CF, and LC helped to analyze and interpret the data. YZ, BC, YY, and

\section{REFERENCES}

Akhade, V. S., Pal, D., and Kanduri, C. (2017). Long noncoding RNA: genome organization and mechanism of action. Adv. Exp. Med. Biol. 1008, 47-74. doi: 10.1007/978-981-10-5203-3_2

Ando, T., Yoshida, T., Enomoto, S., Asada, K., Tatematsu, M., Ichinose, M., et al. (2009). DNA methylation of microRNA genes in gastric mucosae of gastric cancer patients: its possible involvement in the formation of epigenetic field defect. Int. J. Cancer 124, 2367-2374. doi: 10.1002/ijc.2 4219

Bao, L., Yu, Y., Luo, Y., Tian, T., Dong, Y., Zong, H., et al. (2017). Genomewide differential expression profiling of long non-coding RNAs in androgenetic alopecia in a Chinese male population. J. Eur. Acad. Dermatol. Venereol. 31, 1360-1371. doi: $10.1111 /$ jdv.14278

Bierhoff, H. (2018). Analysis of lncRNA-Protein Interactions by RNA-Protein PullDown Assays and RNA immunoprecipitation (RIP). Methods Mol. Biol. 1686, 241-250. doi: 10.1007/978-1-4939-7371-2_17

Boon, R. A., Jaé, N., Holdt, L., and Dimmeler, S. (2016). Long noncoding RNAs: from clinical genetics to therapeutic targets? J. Am. Coll. Cardiol. 67, 1214-1226. doi: 10.1016/j.jacc.2015.12.051
BX helped to analyze the data and draft the manuscript. $\mathrm{KH}$ and CL conceived and designed the study and drafted the manuscript. All authors contributed to the article and approved the submitted version.

\section{FUNDING}

This work was supported by the National Natural Science Foundation of China (Grant Nos. 81501685 and 81972957), the Natural Science Foundation of Guangdong Province (Grant Nos. 2016A030310078 and 2017A030313776), the Natural Science Foundation of Guangxi Zhuang Autonomous Region (Grant Nos. 2017GXNSFBA198046 and 2018GXNSFAA281150), and the Guangxi Thousands of Young and Middle-aged Backbone Teacher Cultivation Program.

\section{ACKNOWLEDGMENTS}

Dr. Stanley Lin is very appreciated for editing the language for this manuscript.

\section{SUPPLEMENTARY MATERIAL}

The Supplementary Material for this article can be found online at: https://www.frontiersin.org/articles/10.3389/fgene. 2020.00694/full\#supplementary-material

TABLE S1 | Primers used to detect the expression of IncRNA H19/mRNAs in human DP cells.

TABLE S2 | Primers used to detect the expression of mRNAs in dorsal skin in NU/NU mice.

TABLE S3 | Proteins binding with IncRNA H19 by biotin-labeled RNA pull-down and mass spectrometry analysis in DP cells (the figures in the Match an Sequence columns represent the number of scores higher than Confidence Threshold).

FILE S1 | The detailed procedure of H19 overexpression lentivirus construction.

Cheng, Y., Gao, Y., Zhao, L., Gao, S., Zhang, G., and Zhang, Y. (2017). Knockout of p16INK4a promotes aggregative growth of dermal papilla cells. Rev. Assoc. Méd. Brasil. 63, 883-889. doi: 10.1590/1806-9282.63.10.883

Fabbri, M., Garzon, R., Cimmino, A., Liu, Z., Zanesi, N., Callegari, E., et al. (2007). MicroRNA-29 family reverts aberrant methylation in lung cancer by targeting DNA methyltransferases 3A and 3B. Proc. Natl. Acad. Sci. U.S.A. 104, 15805-15810. doi: 10.1073/pnas.0707628104

Garzon, R., Liu, S., Fabbri, M., Liu, Z., Heaphy, C. E., Callegari, E., et al. (2009). MicroRNA-29b induces global DNA hypomethylation and tumor suppressor gene reexpression in acute myeloid leukemia by targeting directly DNMT3A and 3B and indirectly DNMT1. Blood 113, 6411-6418. doi: 10.1182/blood2008-07-170589

Ge, M., Liu, C., Li, L., Lan, M., Yu, Y., Gu, L., et al. (2019). miR-29a/b1 Inhibits Hair Follicle Stem Cell Lineage Progression by Spatiotemporally Suppressing WNT and BMP Signaling. Cell Rep. 29, 2489-2504. doi: 10.1016/j.celrep.2019. 10.062

Gong, Y. Y., Peng, M. Y., Yin, D. Q., and Yang, Y. F. (2018). Long non-coding RNA H19 promotes the osteogenic differentiation of rat ectomesenchymal stem cells via Wnt//-catenin signaling pathway. Eur. Rev. Med. Pharmacol. Sci. 22, 8805-8813. doi: 10.26355/eurrev_201812_16648 
He, H., Wang, N., Yi, X., Tang, C., and Wang, D. (2017). Long non-coding RNA H19 regulates E2F1 expression by competitively sponging endogenous miR$29 \mathrm{a}-3 \mathrm{p}$ in clear cell renal cell carcinoma. Cell Biosci. 7:65. doi: 10.1186/s13578017-0193-z

Ikegami, K., Ohgane, J., Tanaka, S., Yagi, S., and Shiota, K. (2009). Interplay between DNA methylation, histone modification and chromatin remodeling in stem cells and during development. Int. J. Dev. Biol. 53, 203-214. doi: 10.1387/ijdb. 082741ki

Jahoda, C. A., Horne, K. A., and Oliver, R. F. (1984). Induction of hair growth by implantation of cultured dermal papilla cells. Nature 311, 560-562. doi: $10.1038 / 311560 \mathrm{a} 0$

Jahoda, C. A., Oliver, R. F., Reynolds, A. J., Forrester, J. C., Gillespie, J. W., Cserhalmi-Friedman, P. B., et al. (2001). Trans-species hair growth induction by human hair follicle dermal papillae. Exp. Dermatol. 10, 229-237. doi: 10.1034/j. 1600-0625.2001.100402.x

Jia, P., Cai, H., Liu, X., Chen, J., Ma, J., Wang, P., et al. (2016). Long noncoding RNA H19 regulates glioma angiogenesis and the biological behavior of glioma-associated endothelial cells by inhibiting microRNA-29a. Cancer Lett. 381, 359-369. doi: 10.1016/j.canlet.2016.08.009

Jiang, H., Zhang, G., Wu, J. H., and Jiang, C. P. (2014). Diverse roles of miR-29 in cancer (review). Oncol. Rep. 31, 1509-1516. doi: 10.3892/or.2014.3036

Kapinas, K., Kessler, C., Ricks, T., Gronowicz, G., and Delany, A. M. (2010). MiR29 modulates wnt signaling in human osteoblasts through a positive feedback loop. J. Biol. Chem. 285, 25221-25231. doi: 10.1074/jbc.M110.116137

Komiya, Y., and Habas, R. (2008). Wnt signal transduction pathways. Organogenesis 4, 68-75. doi: 10.4161/org.4.2.5851

Kornienko, A. E., Guenzl, P. M., Barlow, D. P., and Pauler, F. M. (2013). Gene regulation by the act of long non-coding RNA transcription. BMC Biol. 11:59. doi: 10.1186/1741-7007-11-59

Kozaki, K., Imoto, I., Mogi, S., Omura, K., and Inazawa, J. (2008). Exploration of tumor-suppressive microRNAs silenced by DNA hypermethylation in oral cancer. Cancer Res. 68, 2094-2105. doi: 10.1158/0008-5472.CAN-07-5194

Krugluger, W., Rohrbacher, W., Laciak, K., Moser, K., Moser, C., and Hugeneck, J. (2005). Reorganization of hair follicles in human skin organ culture induced by cultured human follicle-derived cells. Exp. Dermatol. 14, 580-585. doi: 10.1111/ j.0906-6705.2005.00330.x

Kunej, T., Godnic, I., Ferdin, J., Horvat, S., Dovc, P., and Calin, G. A. (2011). Epigenetic regulation of microRNAs in cancer: an integrated review of literature. Mutat. Res. 717, 77-84. doi: 10.1016/j.mrfmmm.2011.03.008

Li, B., Liu, J., Zhao, J., Ma, J. X., and Ma, X. L. (2017). LncRNA-H19 modulates wnt $/ \beta$-catenin signaling by targeting DKK4 in hindlimb unloaded rat. Orthopaed. Surg. 9, 319-327. doi: 10.1111/os.12321

Li, Y., Li, G. Q., Lin, C. M., and Cai, X. N. (2005). One-step collagenase I treatment: an efficient way for isolation and cultivation of human scalp dermal papilla cells. J. Dermatol. Sci. 37, 58-60. doi: 10.1016/j.jdermsci.2004.10.001

Liang, W. C., Fu, W. M., Wang, Y. B., Sun, Y. X., and Zhang, J. F. (2016). H19 activates wnt signaling and promotes osteoblast differentiation by functioning as a competing endogenous RNA. Sci. Rep. 6:20121. doi: 10.1038/srep20121

Lin, C., Yuan, Y., Chen, X., Li, H., Cai, B., Liu, Y., et al. (2015). Expression of wnt $/ \beta$-catenin signaling, stem-cell markers and proliferating cell markers in rat whisker hair follicles. J. Mol. Histol. 46, 233-240. doi: 10.1007/s10735-0159616-5

Lin, C. M., Liu, Y., Huang, K., Chen, X. C., Cai, B. Z., Li, H. H., et al. (2014). Long noncoding RNA expression in dermal papilla cells contributes to hairy gene regulation. Biochem. Biophys. Res. Commun. 453, 508-514. doi: 10.1016/j.bbrc. 2014.09.119

Loginov, V. I., Rykov, S. V., Fridman, M. V., and Braga, E. A. (2015). Methylation of mirna genes and oncogenesis. Biochemistry 80, 145-162. doi: 10.1134/ S0006297915020029

Lu, Y. F., Liu, Y., Fu, W. M., Xu, J., and Li, G. (2016). Long noncoding RNA H19 accelerates tenogenic differentiation and promotes tendon healing through targeting miR-29b-3p and activating TGF- 1 signaling. FASEB J. 31, 954-964. doi: 10.1096/fj.201600722R

Luo, M., Li, Z., Wang, W., Zeng, Y., Liu, Z., and Qiu, J. (2013). Long non-coding RNA H19 increases bladder cancer metastasis by associating with EZH2 and inhibiting E-cadherin expression. Cancer Lett. 333, 213-221. doi: 10.1016/j. canlet.2013.01.033
Nagano, H., Tomimaru, Y., Eguchi, H., Hama, N., Wada, H., Kawamoto, K., et al. (2013). MicroRNA-29a induces resistance to gemcitabine through the wnt/ $\beta$-catenin signaling pathway in pancreatic cancer cells. Int. J. Oncol. 43, 1066-1072. doi: 10.3892/ijo.2013.2037

Nilforoushzadeh, M., Jameh, E. R., Jaffary, F., Abolhasani, E., and Aghdami, N. (2017). Hair follicle generation by injections of adult human follicular epithelial and dermal papilla cells into nude mice. Cell J. 19, 259-268. doi: 10.22074/cellj. 2016.3916

Nozomi, T., Binh, N., and Shinkichi, T. (2017). Hair growth promoting and anticancer effects of p21-activated kinase 1 (PAK1) inhibitors isolated from different parts of alpinia zerumbet. Molecules 22:132. doi: 10.3390/ molecules 22010132

Ohn, J., Kim, K. H., and Kwon, O. (2019). Evaluating hair growth promoting effects of candidate substance: a review of research methods. J. Dermatol. Sci. 93, 144-149. doi: 10.1016/j.jdermsci.2019.02.004

Ohyama, M., Zheng, Y., Paus, R., and Stenn, K. S. (2010). The mesenchymal component of hair follicle neogenesis: background, methods and molecular characterization. Exp. Dermatol. 19, 89-99. doi: 10.1111/j.1600-0625.2009. 00935.x

Rishikaysh, P., Dev, K., Diaz, D., Qureshi, W., Filip, S., and Mokry, J. (2014). Signaling involved in hair follicle morphogenesis and development. Int. J. Mol. Sci. 15, 1647-1670. doi: 10.3390/ijms15011647

Robaina, M. C., Mazzoccoli, L., Arruda, V. O., Reis, F. R., Apa, A. G., de Rezende, L. M., et al. (2015). Deregulation of DNMT1, DNMT3b and miR-29s in burkitt lymphoma suggests novel contribution for disease pathogenesis. Exp. Mol. Pathol. 98, 200-207. doi: 10.1016/j.yexmp.2015.03.006

Rognoni, E., Gomez, C., Pisco, A. O., Rawlins, E. L., Simons, B. D., Watt, F. M., et al. (2016). Inhibition of $\beta$-catenin signalling in dermal fibroblasts enhances hair follicle regeneration during wound healing. Development 143, 2522-2535. doi: $10.1242 /$ dev. 131797

Soma, T., Fujiwara, S., Shirakata, Y., Hashimoto, K., and Kishimoto, J. (2012). Hairinducing ability of human dermal papilla cells cultured under wnt $/ \beta$-catenin signalling activation. Exp. Dermatol. 21, 307-309. doi: 10.1111/j.1600-0625. 2012.01458.x

Tao, S. C., Rui, B. Y., Wang, Q. Y., Zhou, D., Zhang, Y., and Guo, S. C. (2018). Extracellular vesicle-mimetic nanovesicles transport lncRNA-H19 as competing endogenous RNA for the treatment of diabetic wounds. Drug Deliv. 25, 241255. doi: 10.1080/10717544.2018.1425774

Torres, M., Becquet, D., Guillen, S., Boyer, B., Moreno, M., Blanchard, M. P., et al. (2018). RNA Pull-down procedure to identify RNA targets of a Long non-coding RNA. J. Vis. Exp. 134:57379. doi: 10.3791/57379

Upton, J. H., Hannen, R. F., Bahta, A. W., Farjo, N., Farjo, B., and Philpott, M. P. (2015). Oxidative stress-associated senescence in dermal papilla cells of men with androgenetic alopecia. J. Invest. Dermatol. 135, 1244-1252. doi: 10.1038/ jid.2015.28

Vincenzi, C., Marisaldi, B., Tosti, A., and Patel, B. (2019). Effects of a new topical treatment containing several hair growth promoters in women with early female pattern hair loss. Skin Appendage Disord. 5, 146-151. doi: 10.1159/ 000493200

Wan, D. C., and Wang, K. C. (2014). Long noncoding RNA: significance and potential in skin biology. Cold Spring Harb. Perspect. Med. 4: a015404. doi: 10.1101/cshperspect.a015404

Wang, K. C., and Chang, H. Y. (2011). Molecular mechanisms of long noncoding RNAs. Mol. Cell. 43, 904-914. doi: 10.1016/j.molcel.2011.08.018

Wang, T. L., Zhou, C., Shen, Y. W., Wang, X. Y., Ding, X. Y., Tian, S., et al. (2010). Prevalence of androgenetic alopecia in China: a community-based study in six cities. Br. J. Dermatol. 162, 843-847. doi: 10.1111/j.1365-2133.2010.09640.x

Wang, X., Zou, M., Li, J., Wang, B., and Guohua, L. (2018). LncRNA H19 targets miR-22 to modulate $\mathrm{H} 2 \mathrm{O} 2$-induced deregulation in nucleus pulposus cell senescence, proliferation, and ECM synthesis through wnt signaling. J. Cell. Biochem. 119, 4990-5002. doi: 10.1002/jcb.26738

Xiong, Y., Liu, Y., Song, Z. Q., Hao, F., and Yang, X. C. (2014). Identification of wnt/ $\beta$-catenin signaling pathway in dermal papilla cells of human scalp hair follicles: TCF4 regulates the proliferation and secretory activity of dermal papilla cell. J. Dermatol. 41, 84-91. doi: 10.1111/1346-8138.12313

Yang, C. C., and Cotsarelis, G. (2010). Review of hair follicle dermal cells. J. Dermatol. Sci. 57, 2-11. doi: 10.1016/j.jdermsci.2009.11.005 
Zhang, D. M., Lin, Z. Y., Yang, Z. H., Wang, Y. Y., Wan, D., Zhong, J. L., et al. (2017). IncRNA H19 promotes tongue squamous cell carcinoma progression through $\beta$-catenin/GSK3 $\beta /$ EMT signaling via association with EZH2. Am. J. Transl. Res. 9, 3474-3486.

Zhang, L., Cheng, H., Yue, Y., Li, S., Zhang, D., and He, R. (2018). H19 knockdown suppresses proliferation and induces apoptosis by regulating miR$148 \mathrm{~b} /$ wnt $/ \beta$-catenin in ox-LDL -stimulated vascular smooth muscle cells. J. Biomed. Sci. 25:11. doi: 10.1186/s12929-018-0418-4

Zhang, L., Yang, F., Yuan, J. H., Yuan, S. X., Zhou, W. P., Huo, X. S., et al. (2013). Epigenetic activation of the miR-200 family contributes to H19-mediated metastasis suppression in hepatocellular carcinoma. Carcinogenesis 34, 577586. doi: 10.1093/carcin/bgs381

Zhou, J., Yang, L., Zhong, T., Mueller, M., Men, Y., Zhang, N., et al. (2015). H19 lncRNA alters DNA methylation genome wide by regulating s-adenosylhomocysteine hydrolase. Nat. Commun. 6:10221. doi: 10.1038/ ncomms 10221

Zhu, N., Huang, K., Liu, Y., Zhang, H., Lin, E., Zeng, Y., et al. (2018). miR195-5p regulates hair follicle inductivity of dermal papilla cells by suppressing wnt/ $\beta$-catenin activation. Biomed. Res. Int. 2018:4924356. doi: 10.1155/2018/ 4924356

Zhu, Y. B., Wang, Z. Y., Yin, R. H., Jiao, Q., Zhao, S. J., Cong, Y. Y., et al. (2017). A lncRNA-H19 transcript from secondary hair follicle of liaoning cashmere goat: identification, regulatory network and expression regulated potentially by its promoter methylation. Gene 641, 28-85. doi: 10.1016/j.gene.2017.10.028

Conflict of Interest: The authors declare that the research was conducted in the absence of any commercial or financial relationships that could be construed as a potential conflict of interest.

Copyright (C) 2020 Zhu, Lin, Zhang, Liu, Cao, Fu, Chen, Zeng, Cai, Yuan, Xia, Huang and Lin. This is an open-access article distributed under the terms of the Creative Commons Attribution License (CC BY). The use, distribution or reproduction in other forums is permitted, provided the original author(s) and the copyright owner(s) are credited and that the original publication in this journal is cited, in accordance with accepted academic practice. No use, distribution or reproduction is permitted which does not comply with these terms. 